\title{
An Analytical Study of Evaluating Basic Skill Criteria for Becoming Counsellors in Indian School
}

\author{
Dr. Varsha Goyal ${ }^{1 *}$, Mr. Yatish Goyal ${ }^{2}$
}

\section{ABSTRACT}

Counsellors play a pivotal role in developing the future generations. Therefore they have to be properly trained through guidance \& counselling course and inculcate the Cross Cultural Sensitization skill along with Conflict Management skill and Problem Solving skills which is helpful in solving problems of students \& shaping students' behavior and performance. Findings reveal that less perfection in empathy, cross cultural sensitization, conflict management skill problem solving skill affects their counselling.

Keywords: Counselors, Cross Cultural Sensitization Skill, Conflict Management Skill, Problem Solving Skill.

In contemporary societies which are changing very fast and facing every time new challenges which are posed to many problems to students. The challenges include communication revolution, technological advancement and the connection across cultures. Culture diversity is present in a large number of societies. (Pederson, 1990). The changes may also be visualized in development of personality of the students also. When teens cannot successfully overcome the crisis and developmental challenges, they experience psychological distress and substantial disorder occurs in the normal flow of daily life and the emotional, social and cognitive aspects and consequently their personality also gets disturbed. (Gaber et.al. 2002). Challenges in life are a certainty and are unavoidable. Therefore, early on, students must learn how to effectively problem-solve in a collaborative manner.

Counselling is a very important ingredient in shaping students' behavior and performance especially in Indian schools. Though no formal practices are going on in the schools or outside the schools by variety of persons as socially important nearby relatives, teachers, and religious personnel in spite of this need of a good counsellor having the qualities empathy, strong sense

\footnotetext{
${ }^{1}$ Assistant Professor, Amity University Noida, India

${ }^{2}$ Solution Architect in Information Technology MNC

*Responding Author

(C) 2016 I V Goyal; licensee IJIP. This is an Open Access Research distributed under the terms of the Creative Commons Attribution License (http://creativecommons.org/licenses/by/2.0), which permits unrestricted use, distribution, and reproduction in any Medium, provided the original work is properly cited.
} 


\section{An Analytical Study of Evaluating Basic Skill Criteria for Becoming Counsellors in Indian School}

of judgment, Conflict Management Skills, Interpersonal Skills, Cross Cultural Sensitivity Skills, ability to follow up the counselled students and above all, to give recommendations to the administration to solve some issues in every school must be necessary who should also develop confidential relationships with students to help them resolve and cope with problems and challenges Counselling is a face to face situation in which a counselor by virtue of training in skills helps the student (clients) to face, perceive, clarify, solve and resolve his adjustment problems (Ponterotto, et.al. 1995)

Attention to multiculturalism and diversity in schools has been growing and is reflected in the rapidly changing demographics of the United States but in India it is prevailing from very beginning and non formal practices were being made since that time (Pedersen, \& Allen, 1998. et.al.). Multicultural counselors who show an appreciation for the life experiences of culturally different students are generally successful in building a positive helping relationship with their students (Diller \& Moule, 2005). Competent and sensitive multicultural counselors should have competencies that include the following: (a) awareness of his/her own cultural values, biases and assumptions, (b) awareness and understanding because Indian students are forgetting and going away from their own cultural values biases assumptions and understanding. During Counselling process need of certain skills in the counselor has been emphasized so that he can resolve different adjustment problems/issues of the client. Use of the skills assists the client/student to adjust positively to life. (Egbochuku, E.O.2008) Yeh conducted research in 2006, exploring school counselors' perception of Asian American students. The results indicated that counselors face challenges when Asian American students disapproved of counseling, had less parental involvement, overcame cultural barriers, and lacked self-disclosure about emotional distress.

In Indian School NavodayaVidalaya is residential school funded by government, the students come from different rural backgrounds get free education and lodging and are from low socio economic status having family evils, wrong life style bad habbits along with them so it is a very challenging role of the counselor to know and understand them, make relationship with them and to solve their problems. A lack of sensitivity to a client's unique background and experience can result in miscommunication (HPSO)

In India there are some schools which are not residential but are only for the children are true personalities as army officers and central govt. employees some are govt. schools also community schools. Indian teachers are already doing counselling practices non-formally but by knowing their status of necessary important skills and their training requirement the strategies may be planned for future shock of the students. That is why the purpose of the present study is to evaluate the prospective counsellors in terms of the basic skills necessary for counselling gender wise and their Institutional backgrounds on following three aspects.

- Perceived Importance

- Mastery Level

(c) The International Journal of Indian Psychology, ISSN 2348-5396 (e)| ISSN: 2349-3429 (p) | 101 


\section{An Analytical Study of Evaluating Basic Skill Criteria for Becoming Counsellors in Indian School}

- $\quad$ Training Requirement

\section{Objectives:}

1. To evaluate the three skills that is Cross Cultural Sensitivity, Conflict Management Skill and Problem solving skill gender wise and their Institutional background wise on following three aspects. Importance Mastery Level Training Requirement by structured Interview, Focus Group discussion and Self-made questionnaire.

2. To evaluate the effectiveness of soft skills viz Cross Cultural Sensitivity, Conflict Management Skill and Problem solving skill of the counsellors who are undergoing training program in terms of their gender \& institution considering following three aspects

- Perceived Importance

- Mastery Level

- Training Requirement

\section{Significance of the Study}

Counselling plays important role when individuals from different cultures within a society are in social contact, prejudices are born and conflicts arise which becomes hurdle in solving social problems as well as individual developmental problems.

Thus cultural sensitivity skill of the counselor help in conflict management \& problem solving of the students who seek counselling. All of these skills are related with each other.

Keeping in mind the research was planned to study cross cultural sensitization skill, conflict management skill and problem solving skill of the teachers who are pursuing guidance \& counselling course so that the training module should be designed \&planned like wise.

It is important for counselors to develop multicultural counseling skills and techniques to assist their students. Counselors who are not trained in multicultural intervention skills may underestimate the influence of a students cultural background. Thus, they may plan inappropriate counseling intervention strategies. The experiences of culturally different students are different from that of the majority students.

Hypothesis: There exists no significant difference among the counsellors of Indian Schools on following 3 skills

1. Cross Cultural Sensitivity Skill

2. Conflict Management Skill

3. Problem Solving Skills

Problem-solving skills: Professional school counselors use their communication skills and collaboration skills to build relationships and empower others. They demonstrate problem-

(C) The International Journal of Indian Psychology, ISSN 2348-5396 (e) | ISSN: 2349-3429 (p) | 102 
solving skills by effectively for decisions, goals, and actions. Many of the problem-solving models employed in counseling are useful in the advocacy process.

\section{RESEARCH METHODOLOGY}

Survey method was used for this study. For this focus group discussion was conducted to identify the problems of students as they experience in their institution (Navodaya Central School and DIET) Structured questionnaire was used for discussion and on the basis of those questions teachers were interviewed. The responses given by maximum no. of members of the group were considered and enlisted in this way primary data has been collected.

Self generated questionnaire on three skills (Cross cultural sensitization, Conflict management and Problem solving skills) .covering questions related to three aspects that is Perceived importance of skill, Mastery level of skill on Job and Training requirement of skills was used.

\section{Sample Size:}

100 Prospective counsellors affiliated with different schools that is Navodya, Kendriya Vidyalaya and DIET of Rajasthan who were pursuing International guidance.\& counselling course( 2014-2015) organized at Regional Institute of Ajmer \& NCERT were included in the study.

Table No. 1. Gender wise Distribution of Prospective Counsellors

\begin{tabular}{|l|l|l|l|}
\hline Year & Male & Female & Total \\
\hline 2014 & 22 & 28 & 50 \\
\hline 2015 & 20 & 30 & 50 \\
\hline Total & 42 & 58 & 100 \\
\hline
\end{tabular}

Table No.2 Distribution of Prospective Counsellors belonging to different type of school

\begin{tabular}{|l|l|l|l|l|}
\hline Year & Navodaya & Kendriya Vidalaya & DIET & Total \\
\hline 2014 & 18 & 26 & 06 & 50 \\
\hline 2015 & 16 & 24 & 10 & 50 \\
\hline Total & 34 & 50 & 16 & 100 \\
\hline
\end{tabular}

\section{Analysis and Interpretation}

To study the basic skills of Indian teachers undergoing the guidance \& counselling course. We have taken a self generated questionnaire on three skills (Cross cultural sensitization, Conflict management and Problem solving skills) according questions related to three aspects that is Perceived importance of skill, Mastery level of skill on Job and Training requirement of skills was included. A counselor has to give responses as Yes or No. On the basis of these answers a score matrix was prepared and then percentage was taken out which are presented in the following tables.

(C) The International Journal of Indian Psychology, ISSN 2348-5396 (e) | ISSN: 2349-3429 (p) | 103 
An Analytical Study of Evaluating Basic Skill Criteria for Becoming Counsellors in Indian School

Table 3. Gender Wise Percentage of Prospective Counsellors in different aspects of CCS CMS and PS

\begin{tabular}{|l|l|l|l|l|l|l|}
\hline Aspects & $\begin{array}{l}\text { CCS } \\
\text { Male }\end{array}$ & $\begin{array}{l}\text { CCS } \\
\text { Female }\end{array}$ & $\begin{array}{l}\text { CMS } \\
\text { Male }\end{array}$ & $\begin{array}{l}\text { CMS } \\
\text { Female }\end{array}$ & $\begin{array}{l}\text { PS } \\
\text { Kendriya }\end{array}$ & $\begin{array}{l}\text { PS } \\
\text { Kendriya }\end{array}$ \\
\hline Importance & 38.09 & 41.4 & 28.5 & 32.7 & 26.2 & 27.4 \\
\hline Mastery Level & 33.3 & 37.9 & 23.8 & 29.3 & 21.4 & 24.1 \\
\hline $\begin{array}{l}\text { Training } \\
\text { Requirement }\end{array}$ & 80.95 & 79.3 & 76.2 & 72.4 & 71.4 & 70.7 \\
\hline
\end{tabular}

Table No.4, Percentage of Prospective Counsellors according to type of school on three aspects of as in following table.

\begin{tabular}{|c|c|c|c|c|c|c|c|c|c|}
\hline 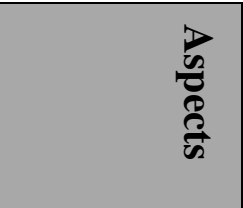 & 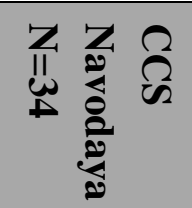 & 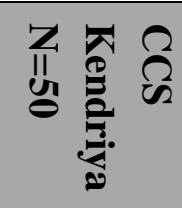 & 苋氜 & 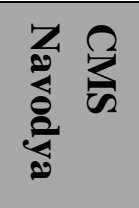 & 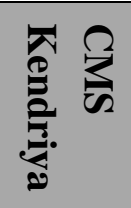 & 兽目 & 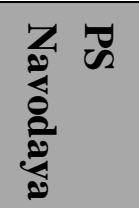 & 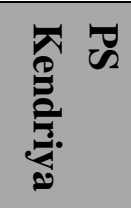 & Ds \\
\hline Importance & 38.2 & 36 & 31.25 & 29.41 & 28 & 25 & 26.5 & 26 & 18 \\
\hline $\begin{array}{l}\text { Mastery } \\
\text { Level }\end{array}$ & 32.35 & 32 & 25 & 23.5 & 22 & 18 & 20.6 & 18 & 12.5 \\
\hline $\begin{array}{l}\text { Training } \\
\text { Requirement }\end{array}$ & 82.3 & 80 & 75 & 76.5 & 76 & 68.7 & 70.6 & 74 & 62.5 \\
\hline
\end{tabular}

Table 3.

Focus group discussion done with the prospective counselors revealed problems of the students, Importance of skills and training requirement in skill is as follows.

In Navodya Vidyalaya students suffer from various adolescent problems, home sickness, impact \& influence of peer group usually make them adopt bad habits. Important skills required are Cross cultural sensitization and Problem solving skills. Training requirement is in Cross culture sensitivity skills.

In Kendriya vidyalaya student's lacks Parental care as their parents are away due to job, the students are taking Coaching for studies so they have less peer group interaction. All in crux we can say that students are emotionally dissatisfied because when they seek someone close to talk regarding their problems they didn't find them. So they suffer from problems of depression which generates importance of culture sensitivity skill, interpersonal relationship and conflict management skill. Requires Training in culture sensitivity skill.

DIET: These are for teacher trainers. Provides short term training of counselling \& guidance to govt. school teachers. Problems which students suffer is that their achievements are low,

(c) The International Journal of Indian Psychology, ISSN 2348-5396 (e)| ISSN: 2349-3429 (p) | 104 


\section{An Analytical Study of Evaluating Basic Skill Criteria for Becoming Counsellors in Indian School}

absenteeism is high because they are engaged in household \& earning activity. Important Skills in which they require training is Cross Culture sensitivity, Conflict Management skill \& Problem solving skill.

Above table revealed that in every aspect of all three skills higher percentage of female reveals more importance \& more mastery level then male teachers and higher\% of male required training more that female.

Table No. 4

Among three scales higher percentage of male \& female show more importance of CCS in comparison to CMS and PS. Less mastery level in comparison to importance but more than their that of CMS and PS. More training is necessary in all the three skills.

\section{DISCUSSION}

This manuscript highlights the importance for soft skills for Indian school counselors to assist students in developing and School Counselor's Role in Facilitating the Development of Students' Soft Skills.

Through fostering and promoting student soft skills as cross culture sensitivity, conflict management \& problem solving, school counselors are in the unique position to recognize student attributes, encourage them to build upon their strengths, identify skills and traits that need to be enhanced, and implement interventions to help students augment these skills, so that they have the opportunity to reach their potential and thrive in a globally competitive society after high school graduation or their post-secondary education.

The Lower percentage of counsellor giving importance to cross cultural sensitivity skill, conflict management and problem solving skill revealed lower mastery in these skills and requirement of training in these skills.

High percentage of counsellor require training in these skills the result supports findings that training in the skills will effectively enhance the students self potential which helps ultimately in developing their personality ( Khera\& Khosla, 2012)

\section{CONCLUSION}

The study emphasizes the status of cross cultural sensitivity, conflict management and problem solving skills in prospective Indian counsellors and training requirement in these gender wise \& according to the need of institutional background. Further finding exposed the need of expanding the identification \& training in these skills at each level in Indian schools as the barriers due to technological advancement and social media badly hindering their all-round personality development. 


\section{An Analytical Study of Evaluating Basic Skill Criteria for Becoming Counsellors in Indian School}

Education may be reformed to inculcate the training in skill in the curriculum, other Education \& Social Agencies should take this role to support the teachers as well as students for all round development to prepare for career.

\section{Scope of Study}

Prospective counsellors of Northern India working in these three types of school and are participant of International Guidance \& Counselling Diploma Course held at RIE in 201415.Central Board of Secondary Education \&Navodaya Schools.

\section{Limitations}

This study is restricted to only teachers who are affiliated to CBSE \&Navodaya Schools as after doing the course of Guidance \& Counselling they will get an opportunity of being an Counsellor in CBSE or other public schools.

\section{Further Research}

Suggestions for Future Research There are several suggestions for future research to further substantiate the stipulation that school counselors help students advance their soft skills in order to be more fruitful in the workforce. Although research has shown that soft skills play a critical role in workplace success (Kamenetz, 2015), it would be advantageous for researchers to determine which specific soft skills have the greatest impact on career readiness and work performance. Further, additional research needs to be conducted in order to assess for the extent to which school counselors are currently teaching and incorporating soft skills into their comprehensive counseling programs. Thus, in the future it would be beneficial to employ a national survey to address the frequency and degree to which counselors currently teach soft skills in order to determine the extent to which soft skills are being taught, as well as raise counselor awareness about the importance of integrating soft skills into the curriculum of school counseling programs are being taught, as well as raise counselor awareness about the importance of integrating soft skills into the curriculum of school counseling programs.

\section{Acknowledgments}

The author appreciates all those who participated in the study and helped to facilitate the research process.

\section{Conflict of Interests}

The author declared no conflict of interests.

\section{REFERENCES}

Pederson, P.B. (1990).The multicultural perspective as a fourth force in counseling. Journal of Mental Health Counselling. 12, 93-95. 


\section{An Analytical Study of Evaluating Basic Skill Criteria for Becoming Counsellors in Indian School}

Garber J, Keily M.K and Martin N.C. (2002). Development of adolescence depressive symptoms: Predictors of change. Journal of Counseling and Clinical Psychology 79-95.

Ponterotto, et.al. (1995).Handbook of Multicultural Counselling, Sage, Thousand Oaks.

Perderson, P. B.(1995). Handbook of Cross-cultural Counselling and Therapy. Greenwood Press. Westport, CT.

Diller, J. V., \&Moule, J. (2005). Cultural competence. Belmont, CA: Thomson Wadsworth

Egbochuku, E. O. (2008). Guidance and counselling: A comprehensive text. Benin city, Uniben Press

Ahadi, et.al. (2009). Effect of problem-solving training on social adjustment and academic performance of shy students. Research on Exception Children 9(3) 193-202.

Khera S and Khosla S (2012). A study of core life skills of adolescents in relation to their self concept developed through YUVA school life skill programme. International Journal of Social Science and Interdisciplinary Research 1(11).

Kamenetz, A. (2015). Non-academic skills are key to success. But what should we call them? Retrieved from http://www.npr.org/sections/ed/ 2015/05/28/404684712/non-academicskills-are-keyto-success-but-what-should-we-call-them.

How to cite this article: V Goyal (2016), An Analytical Study of Evaluating Basic Skill Criteria for Becoming Counsellors in Indian School, International Journal of Indian Psychology, Volume 3, Issue 4, No. 58, ISSN 2348-5396 (e), ISSN: 2349-3429 (p), DIP: 18.01.051/20160304, ISBN: 978-1-365-24976-1 